\title{
Student Centred Teaching And Motivation
}

\author{
Kristina Mullamaa \\ College of World Languages and Cultures \\ Tartu University, Estonia
}

\begin{abstract}
The modern learning environment offers great opportunities for educators and teachers to apply the principles of innovative learning and teaching. In this article we view some relevant aspects of motivation and individualisation as analysed in recent research. We review the following topics: conscious and subconscious motivation; mastery and performance goals, teachers' role as advisers, as well as motivation and the learning context. We approach the topic through the prism of examining the possibilities for supporting and encouraging student-centred learning, as well as increasing student responsibility in their learning process. The focus is on how individualisation and increased responsibility affect students' motivation and thus their capacity to become successful and independent life-long learners. As an illustrative example of how students view the paradigmatic changes, we present the results from our current research project on student-centred learning.
\end{abstract}

Keywords: Motivation, student-centred learning, teacher roles, student support, autonomous learning

\section{Modern learning and teaching paradigms \\ INTRODUCTION}

In tune with the highly dynamic and rapid processes of change in the modern world, the field of education is changing fast. New models for enticing and educating the new, agile "on-line generation" are searched for and found. New methodologies and principles develop as educators discover the new paradigms of the modified acquisition typologies and on-line life consequences to learning patterns and attention spans. In such a quickly changing world, both the studens' and teachers' roles are undergoing a rapid change (cf. Mullamaa 2009, 2016). Teachers develop from instructors to advisers and mentors, who support the broader learning process. Students' responsibility and the demands on their motivation and focusing skills increase.

In this article we will observe the theoretical background of motivation and its practical implications on the modern learning environment, the learner and teacher roles.

\section{Motivation}

Currently, motivation and individualisation related aspects can be seen to be of increasing importance in the learning and teaching process. We suggest that these areas may be seen as some of the stepping stones in developing the modern, facilitating and supporting learning environment. Below, let us briefly analyse the area of motivation with respect to its theoretical implications and possibilities of applying it in practice.

For the learning to happen, there has to be motivation both on the student's and the teacher's side. Motivation has to be aroused so that the will to deal with an activity could occur. Motivation has to be preserved, at a relatively high level, in order for the motivation to last. And last but not least, it would be preferable if motivation could be gradually increased so as to 
enhance the learner's cognitive and affective arousal. This could encourage students to focus on achieving their personal goals. It can also help them to grapple with the learning processes they are going through together with the teachers and significant others. Below, let us take a brief look at some recent highlights that illuminate and analyse the phenomenon and capacity known as "motivation".

For the first, we notice that even if "motivation" is a topic often discussed in multiple theoretical and analytical sources, in fact it proves that motivation is hard to pinpoint and its character is difficult to determine. Thus it is difficult for scientists to define it. Let us see how psychologists describe it. Reeve (2009:10) states:

"Motivation is private, unobservable, and seemingly mysterious experience. You cannot see another person's motivation. /.../ Two ways exist to infer motivation in another person. The first way is to observe motivation's behavioural manifestations. /.../ The second way to infer motivation is to pay close attention to the antecedents known to give rise to motivational states".

To observe the behavioural manifestations of motivation, Reeve suggests (ibid.: 11):

"Eight aspects of behaviour express the presence, intensity, and quality of motivation /.../: attention, effort, latency, persistence, choice, probability of response, facial expressions, and bodily gestures". "Engagement refers to the behavioural intensity, emotional quality and personal investment in another person's involvement during an activity".

In addition to the above, one can rely on self-reports when deciding on the person's motivation, usually in the form of an interview of a questionnaire. This is also what we have used as the empirical basis for the analytical part of this paper. In general, the facts one should remember when researching motivation would according to Reeve be the following:

- Motivation benefits adaptation

- Motives direct attention and prepare action

- Motives vary over time and influence the ongoing stream of behaviour

- Types of motivation exist

- Motivation includes both approach and avoidance tendencies

- Motivation study reveals what people want

- To flourish, motivation needs supportive conditions" ( cf. Reeve 2009:13-14).

Our main focus in this article is on how we could create supportive conditions both for students' self motivation and external motivation.

\section{Conscious and subconscious motivation}

What adds to the vagueness in capturing and defining motivation, is the fact that - also for the people it concerns - it is not often verbalised nor even conscious. In modern motivation theories, it is often stressed that a lot of the actual motivators are in fact unconscious or subconscious, cf.:

"/.../ one of the most interesting recent developments in the social psychology of motivation has been the growing recognition that many kinds of social behaviours are performed in an almost automatic, spontaneous fashion, without conscious awareness. Even more intriguing are a growing number of findings suggesting that not only that social actors are frequently unaware of the real motivational reasons for their behaviours, but more strikingly, that when questioned theyoften come up with clearly incorrect or 
mistaken causal explanations for their actions (Wegner \& Gilbert, 2000 in Forgas et al 2005:1-2).

In their illuminating article the authors (ibid.) set out to define: how "intrinsic and extrinsic, and conscious and unconscious, motivational influences interact in producing social behaviours". Importantly, Wegner and Gilbert stress that in analysing motivation, the role of affect and emotions should not be forgotten. As they put it (ibid: 7):

"/.../ much recent evidence suggests that affective states and moods, however caused, can often be a powerful source of motivated cognition and behaviour. For example, even mild mood states influence how people perceive, interpret, respond to, and communicate in social situations /.../".

A positive atmosphere is the more important, as we know that even the physical responses of our own bodies predict whether a situation is perceived as positive or negative:

"/.../experimental participants who had been asked to adopt a smiling expression judged themselves (i.e. their own well-being) and affective stimuli (e.g., cartoons) more positively. According to self-perception theory, these participants inferred their affective state from their facial expression" (Strack and Deutsch in Forgas 2005: 100).

Furthermore:

"The same logic was subsequently applied to postural expression. Stepper and Strack (1993) found that participants who were introduced to adopt an upright posture while learning about their above-average performance in a previous task felt prouder than participants induced to assume a slumped pose" (ibid.).

Thus (ibid 102): “/.../ unobtrusively manipulated facial expressions may influence evaluative judgements".

\section{Similarly, (ibid. 101)}

"These findings show motor influences on mental processing when the behaviour has no immediate evaluative implications. However, these implications are mediated by a motivational subsystem to which the behaviour belongs. Because nodding is a nonverbal sign for agreement in most cultures and shaking one's head is a signal for disagreement, these head movements are linked to an orientation toward approach or avoidance, which influences the impulsive regulation of behaviour".

Thus, we don't often know what exactly influences us. However, the research results above clearly demonstrate the importance and influence of affect and emotions. This should teach us to 1 ) better and more realistically analyse and "dissect" our real reasons for finding things to be motivating for us; 2) direct students' attention to the fact, so as to help also them see what's behind the lure; 3) design reasonably positive course materials and 4) a supportive and emotionally positive course atmosphere - for them to be able to enjoy it, and raise their motivation.

\section{Mastery and performance goals}

Another aspect to consider is whether the motivation is actually fostered by the will to excel in a certain subject, or just to outperform others. Thus, when designing our learning environment, and supporting and inspiring our students, one should remember the difference between mastery and performance achievement goals. Harackiewicz et al (2005: 24) define these goals as follows: 
"When pursuing mastery goals, an individual's reason for engaging in an achievement activity is to develop competence at an activity. In contrast, when pursuing performance goals, an individual's reason for engagement is to demonstrate competence relevant to others."

Research suggests that for mastery goals students choose more challenging tasks, while for demonstration goals they are rather satisfied with the easier ones (ibid.: 24-25). Thus, creating a positive atmosphere for learning and a safe and encouraging learning environment, can also encourage students to take challenges and broaden their horizons for the purpose of developing the mastery skills.

However, also students' wish to develop their performance skills has some advantages. As shown by Harackiewicz et al, 2005: 25:

" /.../ tasks related to either preference are accepted more easily by the respective learner types. However, there is a positive effect spillover in either of the preferences. For example: " A performance goal /.../ provides the additional challenge of outperforming others and demonstrating competence, and thus may make the game more exciting and interesting for HAMs /individuals high in achievement motivation/".

Reeve (2009: 190) points out:

"Both types of goals - performance and mastery - are common in the culture, and both encourage achievement /.../. But typically, social settings like the workplace, sports field, and classroom pit these two goals against each other and ask (force) workers, athletes and students to pick one goal over the other. People are often asked to choose between courses of action that allow them to:

- Look smart and competent but at the sacrifice of learning something new.

- Learn something new, useful, or important, but at the sacrifice of looking smart and competent."

Thus, it may be important for the teacher as a mentor in the learning process to make use of this important theoretical piece of knowledge. Furthermore, Harackiewicz et al (2005: : 27) conclude that

"/.../ both achievement goals could promote intrinsic motivation. Specifically, positive mastery and performance goal effects depended on personality differences (e.g., whether an individual was characteristically high or low in achievement motivation) or on characteristics of the situation (e.g., the match with other goals in the situation). What's more, by examining the underlying motivational processes, Harackiewicz and Elliot found that mastery and performance goals facilitated interest through the same key mechanisms (competence valuation and task involvement). What proved more critical than the type of the goal pursued was whether the goal fostered competence valuation and task involvement."

It is also significant to observe (cf. Harackiewicz et al. 2005: 31) that both types of achievement goals bring about positive results in academic performance - as this, traditionally, involves both aspects (you have to understand and excel as well as to prove and demonstrate your knowledge at tests). Relevant to our course design and material choice ( but also e.g. e-learning and gamification) is the result Harackiewicz et al (2005: 32, emphasis mine) present that shows that "interest partially mediated the direct effect of mastery goals on continued interest and academic major choice, but/.../ enjoyment did not predict continued interest in psychology or academic major choice." 
This research result supports the widespread assumption that making the learning process intriguing, challenging and activating will stimulate students' learning (cf. Problem Based Learning, Activity Based Learning, Learning through Activity Centres, etc.). The result that "enjoyment did not predict continued interest in psychology or academic major choice" (ibid.), however, seems rather surprising viz a viz the widespread presumption (that enjoying the learning process stimulates (and thus motivates) learning. As it would - at first glance - be logical to assume that people would choose as their academic major subjects those that they enjoy learning, the result by Harackiewicz et al. above makes the point that not only enjoyment but also interest have to be present in order for the motivation to persist.

Closely related to this are the catch and hold aspects of interest which also play an important role in learner motivation (Harackiewicz et al. 2005: 36):

"/.../ catch factors changed the initial experience of the task that it was more fun to learn about the tasks presented, whereas hold factors seemed to affect individuals' evaluation of the topic. Continued interest may depend on both enjoying the learning experience and finding the material interesting and important. The enjoyment of a learning task will soon be forgotten if the task was not perceived as valuable".

Obviously, the conclusion is highly relevant for teachers. Be it the materials-design, the possible introduction of gamification-ideas in the learning process, stimulation through games, credit points and achievable but motivating steps of process - all these popular methods can be applied in addressing the psychological mechanisms behind learning described above.

\section{Teacher-student roles and trust}

\section{Students' emotions and teachers' roles}

Above we have seen the importance of subconscious and unconscious motivation, affect and emotions, as well as the performance and mastery goals on student motivation. Obviously, these are strongly influenced by the cooperation partners of students, including their peers, family and teachers.

In many contexts "only data-forwarding"-focused teaching is still considered paramount. In many others - the role teachers have in designing the emotional environment in a classroom, as well as the importance of the support offered by them, is clearly stressed. Teachers have been considered as "emotional amplifiers", and "motivational socialisers" in the classroom. As expressed by Dörnyei (2001:35, emphasis mine):

"/.../ teachers are powerful motivational socialisers. Being the officially designated leaders within the classroom, they embody group conscience, symbolise the group's unity and identity, and serve as a model or a reference/ standard. They also function as an 'emotional amplifier' of the group whose appeals and examples are critical for mobilising the group /.../. Simply speaking, to lead means to direct and energise, that is, to motivate".

Similarly to what we have expressed before (cf. Mullamaa 2009, 2011, 2016), Carnell and Lodge (2002: 23) stress the importance of trust and positive relationships in learning. They state (ibid.):

"Learning is best promoted in a context of trust, respect and confidence. Pressure and high expectations can be damaging".

Carnell and Lodge (2002: 23) point out the influence factor of "significant others". Importantly, the teachers are demonstrated to have an essential role in this: 
"Young people recognize the value of good relationships with adults for effective learning. In their interviews with over 300 secondary students in Wales, Morgan and Morris found that pupils saw good learning as overwhelmingly derived from the actions of teachers, and that good relationships with the teacher was an important factor in this (Morgan and Morris, 1999)".

More than just direct learning outcomes, a positive teacher-student relationship can influence student school adjustment and - we suggest - through this even the pleasure of attending school and becoming an educated person altogether. Meyer and Turner (2007: 248) point out:

"Teachers' relationships with students have been found to be associated with students' academic achievement and school adjustment. /.../ Emotional scaffolding can help to establish and sustain positive relationships and classroom climate that support student engagement, learning and perceptions of competence. /.../

Furthermore, Carnell and Lodge (2002: 23, emphasis mine), claim:

"We have noted that young people are often dependent on adults, especially teachers. This observation is supported by our research with one group of Year 10 students. They valued teachers who responded to the particular class, taking account of their profile of needs. They valued teachers who make an extra effort, like making themselves available to help a young person. They identified three kinds of teachers: those who just do a job, those who are enthusiastic and enjoy passing on their knowledge of their subject, and a third group who live for teaching."

Thus we have proof that students both notice, monitor and evaluate "good teaching" and measure the persons working with them up to the idealised picture they have of them. Their expectations are high, and this can hopefully motivate also teachers to live up to them.

In the same vein, Kiggins and Cambourne (2007: 368-379) emphasise the importance of a "triadic partnership" from the very beginning of training of young teachers. They state "/.../ trust becomes a required element in the knowledge building process, and if friendship and trust are not present among the student cohort, this process is unlikely to occur" (ibid. 374).

These principles are well-known, and some pedagogical approaches (e.g. the socio-emotional environment supporting approach used in Norwegian schools), seem to apply them consciously and systematically. Teachers try to be supportive and encouraging, providing students with the educational, motivational and also emotional support they need. Undoubtedly, this is the goal to strive for, and it can foster and support good teacher-student cooperation, and through this also student motivation.

In addition to the example of Norway above, also Meyer and Turner (2007: 245) suggest that teachers should "scaffold" emotions in the classroom:

"scaffolding emotions in classroom" include " setting a positive emotional tone, building shared understanding, extending understanding, and supporting empathy and mutual respect."

Importantly, their research illuminates a clear link between the emotional atmosphere in the classroom and the learning outcomes:

"In our analyses of classroom discourse to discover the instructional characteristics that promote high levels of student involvement in learning, we have found emotional scaffolding to be critical in sustaining students' understanding of challenging concepts, 
students' demonstration of their competencies and autonomy, students' involvement and persistence, and students' emotional or personal experiences /.../" (Meyer and Turner 2007: 245).

In addition to the above, we suggest, the teacher's role, as that of a positive role model, should be stressed. As we have pointed out in our earlier research (cf. Mullamaa 2009, 2011, 2016), teachers are seen as guidance and role models, both as concerns learning, academic dignity, but also the communication models in and equal respect sharing towards the group members.

How about the negative effects teachers might have on students? Although this often seems to be a taboo-topic, research has been carried out in this field as well. And research very clearly points to the negative effect of cold socio-emotional environments on students in the classroom, cf. Meyer and Turner 2007: 249:

"Our analyses of ambiguous and negative classroom socio-emotional environments were related to student reports of more avoidance behaviour, whereas in supportive classrooms, students reported significantly lower incidences of avoidance behaviours. Consistent, positive emotional scaffolding appears to have helped establish the necessary foundation of trust needed for taking the risks and accepting the responsibility so essential to learning in classrooms".

Thus, positive support is the best support in student achievement, as is confirmed by the authors' (ibid. 253) reference to a study by Stipek et al 1998, which shows that "affective climate was the best predictor of student motivation and that positive affect was associated with mastery orientation".

Thus, in providing support to students, teachers should remember that also teacher emotions play a crucial role on students' learning motivation. As stated by Schutz et al ( 2007: 227, emphasis mine):

"As teacher identity and emotions are inevitably related to each other, teacher identity is often conveyed and expressed through emotions, whether it is unconscious or conscious".

Thus, teachers need to constantly monitor themselves as sources for cues of how learning and the learning situation may be perceived, at the same time following the implicit rules for discipline, emotional well-being of the group, and a positive environment in the classroom.

In the same vein, Schutz et al (ibid. 231) further point out:

"/.../ within the context of classroom activity settings, teachers are expected to display emotions in particular ways depending on the nature of the events /.../. For example, in most transactions with students, teachers are expected to show pleasant emotions and suppress their unpleasant emotions /.../".

\section{Motivation and student feedback}

Above we have reviewed some theorists' views on motivation and learning. But how do students themselves evaluate what's important for their learning and motivation?

To illustrate this, I am going to present some excerpts from student feedback to an article on active learning that we read and discussed with them in the autumn of 2015. Altogether 38 students responded, and their task was to analyse their preferred learning pattern viz a viz what they experience in their current university and what they have experienced earlier - i.e. during their high-school studies and at other universities. 
The focus was on the discussion on motivation and we approached the topic through the prism of student centered (i.e. intrinsic) versus teacher centred (i.e. extrinsic) motivation. Below, we bring examples from some student posts. We have asked for their agreement for this, and they were happy to share their views, and I have promised them that they remain anonymous.

\section{THE EMPIRICAL PART: OUR STUDY AND RESULTS}

\section{Students feedback and analysis of their learning process}

\section{Motivation and student feedback}

Above we have reviewed some theories on motivation and learning. But how do students themselves evaluate what's important for their learning and motivation? To find out, I invited students to discuss on the topic of student based-teacher based learning. In relation to this, we intended to get a glimpse of their understanding of the learning process and the importance of motivation for them. The implicit questions included: "Does student-centred vs teacher-centred teaching have a role in influencing student motivation? How important is intrinsic motivation in student centred learning and do they appreciate it?" To illustrate the answers, I am going to present some excerpts from student feedback.

\section{METHODOLOGY}

The methodological framework is ethnographic research. Qualitative inputs are patterned and quantified. We use the method of on-line discussion, where students write their opinion into the e-learning environment Forum. The e-learning platform is Moodle. Students are familiar with the process, as we use this way of discussion also for other topics during the course.

We presented the questions on motivation and student- $v$ s. teacher focused learning to our two groups of English Advanced students during the academic year 2015/16. To initiate a discussion, the students read through a short text on modern learning. After reading the article, all students were encouraged to enter their views on the topic in our common e-learning environment ( Moodle Discussion). This is a standard procedure during our e-learning block of learning. Thus, the procedure itself was a rather routine one, students feel comfortable concerning the task itself ( as there are several texts and topics we discuss in the same fashion).

The procedure is, that after reading the article, students enter their comments on the topic in the Forum. Altogether 36 students responded, and their task was to analyse their preferred learning pattern concerning student-centred and teacher-centred learning. They also analysed this viz a viz what they experience in their current university (Tartu university) and what they have experienced earlier - i.e. during their high-school studies and at other universities. This is the basis for our empirical results on the student views on the issue. Students have been numbered from 1-36 based on the number of entering their point in the on-line groupdiscussion. The abbreviation "S" stands for "student". Thus, "S1" means "Student 1", "S32" "Student 32", etc.

Students were informed about the fact that we are interested in their views on this discussion, and that their answers and data will be used for research. They also gave their consent and support for this. Their quotes are given verbatim (and without editing) to illustrate the results.

In addition to the on-line discussion and its results, we also had three focus group interviews with the students: in the beginning, in the middle, and at the end of the course. We also had individual feedback and study process analysis sessions with individual students at the end of the course. The focus group interviews and individual interviews consolidated the results. 
They were thus used as a reference point for "gauging the self-evaluation process" of students, confirmatory to the current research results, but due to space constraints, have not been included in this paper.

\section{Overview and illustration}

\section{RESULTS}

The analysis of our 36 students' entries in the on-line discussion environment gives the following results:

1. In general, the balance between student-centred and teacher-centred learning

process is seen to be important by the majority of students. 30 out of our 36 respondents mention it as favourable. Excerpts from student on-line discussions to illustrate this view include:

S1: I would prefer a mixed one meaning a balance of student-centred learning and teachercentered learning. On the one hand it is a good idea to put a schoolchild/student in the center where he/she can decide what he/she will learn, how he/she will learn, and how he/she will assess their own learning. On the other hand it can be very abusive from schoolchildren/students applying these rules. Thus, I agree that it is sometimes good to have a section that is pre-planned to order the learning process and some limits to the studentcentred learning should be set.

S2: Well, I strongly believe that student-centered learning is much more effective and interesting than old notion of classroom, where students were just sitting quietly and neatly in their seats, while the teacher was up front pouring wisdom and knowledge into their brains. Student-centered approach develops autonomy and independence by putting responsibility in our hands. Apart from getting education in more efficient way, student-centered learning helps us to develop many practical skills, which are necessary in our everyday life - being independent, confident, responsible, able to control your time, plan your schedule, etc. But I agree with Artem and prefer some kind of mixed approach. I don't think we should throw away every aspect of teacher-centered learning. It is better to have a pre-planned section very often. There are courses, which include a huge amount of reading materials and you need right direction and advice, which of them are most important. Professors can help you with their experience and knowledge. Also, it would be quite confusing and disorganized if every student could chose only what they wanted to learn.

S6: I would also agree with the majority opinion with regard to mixed approach in higher education. If it was only self-management and self-studying, why would we need universities at all? Just to give us costly papers which are called "diplomas"? Self-learnerns do not seem to need them. I believe that we are going to universities for a such combined approach. Due to the fact that we are not a professionals in all the subjects we are going to study, we need people who are indeed professionals to give us guidance and correct our mistakes within the process. That is the function of each university which creates big part of its economical and social value.

S7: Student-centred learning is more interesting, but we still need teacher-centred learning too. Teacher directs all classroom activities, so they don't have to worry that students will miss an important topic. Also when students work alone, they don't learn to collaborate with other students, and communication skills may suffer. I agree that it is best to use a combination of approaches.

S9: Students graduating from high school is familiar with teacher-centred teaching method because it is how they were taught through out their schooling. They are unused to get involve in the lectures, to find their own reading materials besides provided textbooks and to discuss 
in a group. Technically, the teacher-centred system exacerbate students' impetus to learn new themselves. They stay passive and expect for knowledge to be filled with.

Fortunately enough, there is a tendency of shift in teaching method from teacher-centred to student-centred. Students are now aware of what they want to study and how to plan their study schedule. Their autonomy has been estimated and raised properly.

However, students might not adapt to the new method immediately. They feel lost in making decision when they have no clues how to choose proper subjects to study. It is when the role of teachers has been addressed. Teachers should be the one who guide and instruct students through their study, yet not to nurture with ready-to-serve knowledge. Teachers will give feedback on how good students have worked and what could be improved.

2. Only student-centred learning is explicitly favoured by four participants. The examples include e.g.:

S11: In common with the most of you I strongly believe that student-centered learning is the best alternitive to form responsible, independent and confident humans.

Luckily this is more often the norm than the exception in University and the future tendency in primary-, middle-, and high school. The very fact, that the progressive educational movement consider 100 years ago, that the assignment of a teacher/professor is to go along with the student, not to educate him/her, make it clearly recognizable!

S16: I agree that student-centred learning is definitely more effective and students should take control of their learning process to become more independent. In elementary school it is inevitable that teachers have to keep more eye on their pupils, but at the same time it is also important to introduce them step-by-step individual learning skills. But in high school and university most of the learning should be done individually in order to avoid the "spoon-fed" students crisis to occur.

3. The importance of skilful guidance by teachers is clearly expressed in several cases:

S 35: Nevertheless, although student-centered learning is the very model of a learning process, I am of the view that better learning outcomes can be achieved if student-centered learning is complemented with teacher-centered learning. The teacher's role is essential in a study plan, not to spoon-fed students but to support them and guide their self-regulated learning to make sure that individuals are flourishing.

4. There were also students who explicitly stated that the existence of teacher-support is necessary for them:

S24: Student-centered learning is more interesting than teacher-centred, but if we have only student-centred learning, there will be problems. For example, when students work alone, they do not developing their communications skills. The students may become lazy and may be they don't feel the importance of learning.

Teacher directs all the activities that the students have to do, helps students and give them feedback. The students don't miss any particular topic.

S34: I think, especially after reading this text, that for me it is easier if everything has been done for me. Although I like making my own systems, I usually don't get to do them, because of the lack of time I have. On the other hand, I don't want to be totally spoon-fed, because I love to 
practice the things I have learned to make them comfortable to use and to feel like they are my own. So the best for me would be to have some part of the learning process pre-planned, so I could fill the other part as I want and feel I should be doing this.

5. Even when the teacher-centred approach is favoured, some students still add they would not like to give up their independence:

S16: I agree that student-centred learning is definitely more effective and students should take control of their learning process to become more independent. In elementary school it is inevitable that teachers have to keep more eye on their pupils, but at the same time it is also important to introduce them step-by-step individual learning skills. But in high school and university most of the learning should be done individually in order to avoid the "spoon-fed" students crisis to occur.

Luckily, I feel that the Estonian education system is student-centred and students are closely involved in the learning process. I personally even prefer when I can plan my time independently and design my learning process

S23: Young adults need to plan their time and set personal goals. I think that if everything is pre-planned for them, they can't really deal with the pressure once they have to step „into the real world".

6. The majority of the students participating in the study, however, also stressed the importance and relevance of student responsibility, cf.:

S3: As most of you, I think that even though student-centered learning could be quite enriching, it's necessary to combine it. If you have everything pre-planned, how are you going to survive after university? Who's going to guide you? It's important to be independent, improve your creativity and most of all, gain responsibility as soon as possible.

S5: I found idea of self-education very inspiring and efficient for students. It is an excellent way to gain responsibility and to get used to adult world. Spoon-fed students can face some difficulties in real world after graduating university, even despite of their good results. This kind of people can suffer from lack of creativity and are not able to think out of frames. But those qualities are what employers want to see in specialists and what are needed for successful entrepreneurship. A particular attitude towards knowledge gives wish to continue study and is a perfect start for life-long learning.

S7: /.../ It is easier to achieve your goals when you can yourself design your learning process and materials. You put your time and effort in it, so you do it more efficient and you have better results./.../ "Spoon-fed" students don't have their own opinion, have a lack of imagination. They also cannot bring their examples. They believe everything the teacher says. Students should be allowed to express their own opinion and most important - have their own opinion!

7. A clear connection between motivation, and the teachers' responsibility to motivate, is expressed:

S32: I just want to add that if you really want the going to school, attending the courses kind of education to work, it is very important how you deliver the knowledge to to students. Many times teachers do not know how to teach. Because as a teacher, you are also a entertainer, speaker, actor. Looking at you teaching must take all my focus and must be fun. Therefore even if some teachers are very good in their field of knowledge, it is no use if their are boring and not appealing. And more important then presenting particular information, I like better when 
teacher creates a curiosity and motivates me. And then let me find the most proper materials, and the best way for me how to get my head around the topic.

What I mean is for example, when Jacque Fresco was teaching his son how to read, he would read him every evening very good book. One night he was like .... "and then in the final moment ... " You know what son I don't really feel like reading it anymore, good night. If you want to know what happened learn how to read. And soon after this his son started to learn how to read by himself because he wanted to. Teacher should learn how to motivate students.

8. Ideal teacher role. Student expectations of teachers are high, and the ideal teacher involvement is described in a couple of cases:

S23: But also I think that teachers are still very important for an effective studying process. I believe that nowadays teacher role has changed more into a tutor role - they show students a direction for moving forward. They are more like guides in this supersaturated modern world, where it is really hard to orientate in the information field.

S32: . Because as a teacher, you are also a entertainer, speaker, actor. Looking at you teaching must take all my focus and must be fun. Therefore even if some teachers are very good in their field of knowledge, it is no use if their are boring and not appealing. And more important then presenting particular information, I like better when teacher creates a curiosity and motivates me. And then let me find the most proper materials, and the best way for me how to get my head around the topic.

What I mean is for example, when Jacque Fresco was teaching his son how to read, he would read him every evening very good book. One night he was like .... "and then in the final moment ... " You know what son I don't really feel like reading it anymore, good night. If you want to know what happened learn how to read. And soon after this his son started to learn how to read by himself because he wanted to. Teacher should learn how to motivate students.

To sum up, 4 of 36 students explicitly favoured student-centred teaching, 4 teacher-centred and 28 obtained a "middle stance", stating there should be a good teacher planned and run framework, yet students individuality and freedom should be respected. Views on teacherstudent cooperation include student responsibility, integrity. Importantly, also the need for the teachers to provide a clear framework and support, motivate and inspire, was mentioned.

The well-balanced student-teacher cooperation thus, clearly gained the upper hand among all the opinions given and - at least based on this sample - seems to be the one to be followed in cooperation with students, in order to encourage and motivate them best.

\section{DISCUSSION}

In this paper we have taken a look at some recent theorists' views on motivation. We reviewed some of the recent literature concerning the aspects of conscious or unconscious motivation, achievement goals or mastery goals, and motivation and affect and emotions. The importance of the student-teacher roles, teacher modelling, support and creating a positive atmosphere was mentioned.

In the empirical part we gave an overview of the pilot-study of a student e-environment based discussion on whether students favour the student-centred or teacher-centred learningteaching model, and if and what kind of connection this may have to motivation. 
The majority of students favoured the "balanced view" with both student and teacher centred approaches combined. Typically, students emphasise they need a well thought through course structure and lesson-plan, which accommodates students' interest- and career-focused choices. These they wish to envision and follow the course goals themselves. The process of learning, the why we do it, as well as the more general goals in life become all the more important for students, and their role entails learning to take this responsibility, as well as to learn to cooperate with teachers, seeing them as partners on this way.

A great proportion of students ( 30 out of 36) stated that they highly valued the possibility to take responsibility and participate in the part allowing them to design the course goals, aims, and materials. This attitude in the sample group consolidates the understanding that modern students need to be seen as equal partners in the learning design. They are willing to and capable of taking the responsibility. They see this opportunity as an integral part of a good quality course-design and teaching.The empirical part of the paper illustrates that students in the sample studied indeed $d o$ appreciate the individualisation and participation in course build-up and practice. They state they appreciate if there is a good balance in a pre-prepared course framework and the assignments they are allowed to designed based on their own career needs and wishes. Thus we can conclude that student-centered learning and teaching is essential for students. The aspects of motivation mentioned in the literature review are of considerable importance for knowing how to better accommodate for this. Motivation, student-centred learning and teaching form an important triangle where finding the right balance supports students and teachers alike.

\section{References}

Brophy, Jere. 2004. Motivating Students to Learn. Second edition. Lawrence Erlbaum Associates, Publishers. Mahwah, New Jersey, London.

Carnell, Eileen and Lodge, Caroline. 2002. Supporting Effective Learning. Paul Chapman Publishing. A SAGE Publications Company. Great Britain, Cromwell Press, Trowbridge, Wilts.

Copage, Judy. 2013. The power of choice: motivation through learner autonomy. Lecture given at the further education training of English teachers in Estonia on March 5, 2013. Organised by Pearson and AS Dialoog, hotel London, Tartu.

Dörnyei, Zoltan. 2001a. Teaching and Researching Motivation. Pearson Education Limited. Malaysia, LSP.

Dörnyei, Zoltan. 2001b. Motivational Strategies in the Language Classroom

Forgas, Joseph, Williams, Kipling, Laham, Simon. 2005. Social Motivation. Conscious and Unconscious Processes. Cambridge University Press. Cambridge, New York, Melbourne, Madrid, Cape Town, Singapore, Sao Paulo, Delhi.

Harackiewicz, Judith, Durik, Amanda, Barron, Kenneth. 2005. "Multiple Goals, Optimal Motivation, and the Development of Interest”. In: Forgas, Joseph, Williams, Kipling, Laham, Simon. 2005. Social Motivation. Conscious and Unconscious Processes. Cambridge University Press. Cambridge, New York, Melbourne, Madrid, Cape Town, Singapore, Sao Paulo, Delhi. 21-40.

Kiggins, Julie., Cambourne, Brian. 2007. The knowledge building community program. In: T. Townsend, R. Bates (Eds.), Handbook of Teacher Education. Globalization, Standards and Professionalism in Times of Change. Springer, printed in the Netherlands. 365-381.

Meyer, Debra, Turner, Julianne. "Scaffolding Emotions in Classrooms”. In: Schutz, Paul and Pekrun, Reinhard. 2007. Emotion in Education. Academic Press, Elsevier. Amsterdam, Boston, Heidelberg, London, New York, Oxford, Paris, San Diego, San Fransisco, Singapore, Sydney,

Mullamaa, Kristina. 2009. Ethics in Teaching. Should We Do More? In: Humanising Language Teaching Magazine.

Year 11; Issue 3; June 2009. Canterbury, England. http://www.hltmag.co.uk/:; http://www.hltmag.co.uk/jun09/sart01.htm 22-35.

Mullamaa, Kristina. 2011. The challenges and opportunities of on-line language teaching. Humanising Language Teaching, 13(1), 12 - 24. England. 
Mullamaa, Kristina. 2016. Teachers as Supporters in the Modern Learning Process. In: Emerging Horizons. Tartu University Press.

Reeve, Johnmarshall. 2009.Understanding Motivation and Emotion. Fifth edition. John Wiley \& Sons, INC. USA.

Schutz, Paul and Pekrun, Reinhard. 2007. Emotion in Education. Academic Press, Elsevier. Amsterdam, Boston, Heidelberg, London, New York, Oxford, Paris, San Diego, San Fransisco, Singapore, Sydney, Tokyo.

Schutz, Paul, Cross, Dionne et al.. 2007."Teacher Identities, Beliefs and Goals Related to Emotions in the Classroom". In: Schutz, Paul and Pekrun, Reinhard. 2007. Emotion in Education. Academic Press, Elsevier. Amsterdam, Boston, Heidelberg, London, New York, Oxford, Paris, San Diego, San Fransisco, Singapore, Sydney, Tokyo. 223-243.

Strack, Fritz, Deutsch, Roland. "Reflection and Impulse as Determinants of Conscious and Unconscious Motivation. In: Forgas, Joseph, Williams, Kipling, Laham, Simon (eds.). 2005. Social Motivation. Conscious and Unconscious Processes. Cambridge University Press. Cambridge, New York, Melbourne, Madrid, Cape Town, Singapore, Sao Paulo, Delhi. 91-113. 